\title{
AN INTERESTING PHENOMENON IN A CASE OF ECTOPIA LENTIS
}

\author{
BY
}

\section{E. V. SRINIVASAN}

MADRAS

AN obese girl of the age of 11 years was brought to my office with symptoms of failing vision. She is an offspring of consanguinity with no other characteristic history. On examination, the right cornea had a nebula near the lower quadrant, said to be due to an attack of small-pox. The pupils of both eyes were rather eccentrically situated and very active, disclosing on dilatation two areas, one clear and the other whitish. The iris was very tremulous in both eyes. The chambers were quite deep and of equal depth throughout. Tension $\overline{\mathrm{c}}$ Maclean's tonometer was $70 \mathrm{~mm}$. in the right and $60 \mathrm{~mm}$. in the left eye. Vision : R.E. $=0$ and vision in the L.E. $=6 / 24 \bar{c}+10.0$ D. sph.

The lenses had the whiteness of a thin ricewater congee, were extremely tremulous and displaced downwards and inwards. The upward and outward aphakic area of the dilated pupil, admitted easily of an ophthalmoscopic examination which revealed a pale disc in the left eye and a pale and cupped disc in the right sightless eye. The same area showed, under the slit-lamp, parallel strands of zonular fibres, each fibre having two to five iridic knots on it. No fibre was loosely hanging-being firmly attached at either end. Just as I was finishing the examination, a doctor friend entered and $I$ asked him to have a look at the interesting case. He quickly remarked that the lens in one eye was in the anterior chamber and to my surprise I did find in one eye the lens had wandered into the anterior chamber, now looking very much like an airbubble - rather a flat air bubble, with a sparkling edge, absolutely immobile, fixed in front of the pupillary area. This phenomenon lasted only for a few seconds, the lens wandering back to its first position of dislocation. Nevertheless, I once succeeded in dislocating it in one eye into the anterior chamber by keeping the head in the prone position for a long time, but failed to continue to keep it there for any appreciable length of time, even by throwing the head forward for a long time and by trying to render the pupil contracted by eserine, subsequent to its dislocation anteriorly. I saw the phenomenon occurring in both eyes on independent occasions. This has been observed by the mother on several occasions only during the last seven months, though she says that for weeks it sometimes does not occur. The patient is conscious of the event by the probable changed character of the vision. The unfortunate part of the whole case is this evanescent 
sojourn of the lens in the anterior chamber and the total impossibility of binding the wanderer there by any ophthalmological trick, sadly disallowing the study of the lenticular border under the slit-lamp.

\section{ABSTRACTS}

\section{I.-CORNEA}

(1) Bauer, A. (Vienna).-The origin of Krukenberg's spindle. (Zur Genese der Krukenberg-Spindel). Zeitschr. f. Augenheilk., Vol. LXXIII, p. 360, 1931.

(1) Bauer reports two cases of Krukenberg's spindle and critically reviews the literature on the subject. A tabulated summary of the findings in published cases is given. The association of Krukenberg's spindle with myopia, adult life, female sex and familial disposition is stressed. Persistent pupillary membrane and other malformations that have been observed are regarded as coincidences. No evidence for any congenital origin of the condition is found. The conflicting views as to the site of the pigment, whether in front of, or behind the endothelium are discussed. That pigment deposits in the cornea may occur apart from Krukenberg's spindle is pointed out.

On the nature of the pigment, Bauer finds no support for the view that it is haematogenous in origin. He holds that it is derived from the melanin so abundantly present in the pigmented tissues of the eye, the pigment being liberated by chronic degenerative processes. Once it is freed it is only a matter of physics to explain the characteristic appearance of the spindle. Ehrlich's experiment in injecting fluorescein into the ear-vein of a rabbit and seeing it trickle down in the anterior chamber as a centrally placed vertical line is recalled, as is Türk's further work showing this phenomenon to be based on convection currents induced by slight differences in temperature. Given a very slow entry of pigment cells into the fluids of the eyes, the differences in temperature between the anterior chamber and vitreous (up to $5^{e}$ according to Michel and Silex) is more than enough to set up convection currents (only $2 / 10^{\circ}$ being necessary according to the author's experiments). The formation of the spindle is facilitated by a slowing down of the convection current, and also by the deep anterior chamber seen in high myopia and megalo-cornea. Physiological bedewing of the endothelium in the pre-pupillary area, shown to be present in about 50 per cent. of children (Lüssi), is another factor which helps the. deposition of the pigment.

ARNold Sorsby. 